\section{Ciprofloxacin susceptibility of Salmonella enteric serovar Typhi and Paratyphi A from blood samples of suspected enteric fever patients}

\author{
Adhikari D,1 Acharya D, ${ }^{*}$ Shrestha P, ${ }^{1}$ \\ Amatya $\mathbf{R}^{3}$
}

\footnotetext{
${ }^{1}$ Department of Microbiology, Kathmandu College of Science and Technology, Kalimati Kathmandu, Nepal, ${ }^{2}$ Department of Microbiology, Kathmandu University School of Medical Sciences, Kavre, Nepal, ${ }^{3}$ Department of Microbiology, Nepal Medical College Teaching Hospital, Jorpati, Kathmandu, Nepal
}

*Correspondence to: Mr. Dhruba Acharya, Department of Microbiology, Kathmandu University School of Medical Sciences, Kavre, Nepal, email: dhruba099@gmail.com, Tel. No.: (+977)-9841456286

\begin{abstract}
INTRODUCTION: Enteric fever caused by Salmonella enterica serovars Typhi and Paratyphi $\mathrm{A}$ is the common clinical diagnosis among febrile patients presenting to hospital in Nepal. The aim of this study was to evaluate the ciprofloxacin (CIP) and other antibiotics susceptibility patterns of Salmonella enterica serovars Typhi and Paratyphi A from blood samples of suspected enteric fever patients visiting KIST Medical College, Kathmandu.
\end{abstract}

MATERIALS AND METHODS: Antibiotic susceptibility test was performed by Kirby Bauer disc diffusion method as per CLSI guidelines whereas MIC determination of ciprofloxacin was performed by agar dilution method.

RESULTS: Altogether 64 presumptive Salmonella spp. were isolated from 840 blood samples of suspected enteric fever patients, of which 41 were $S$. Typhi and 23 were $S$. Paratyphi A. All Salmonella spp. isolates were sensitive to ceftriaxone and ofloxacin whereas 4 isolates were resistant to ciprofloxacin. One isolates each of $S$. Typhi and $S$. Paratyphi A were multidrug resistant. Fifty five isolates of Salmonella spp. were resistant to nalidixic acid (NA) with higher rate in $S$. Paratyphi A (91.3\%) compared to $S$. Typhi (82.9\%). MIC determination of ciprofloxacin revealed that majority of the isolates were resistant to ciprofloxacin and 2 isolates were resistant with MIC value of $4 \mu \mathrm{g} / \mathrm{ml}$ and $8 \mu \mathrm{g} / \mathrm{ml}$. Importantly, we found simultaneous presence of NA resistance and decreased susceptibility to CIP suggesting that resistance to NA is a reliable indicator of decreased CIP susceptibility.

CONCLUSIONS: Disc diffusion test failed to detect the reduced susceptibility of ciprofloxacin. Hence the MIC determination of ciprofloxacin against Salmonella spp. isolates would be important.

KEY WORDS: Enteric fever, Salmonella, Ciprofloxacin MIC

Article submitted 12 June. Reviewed 10 July. Author correction 10 August. Final version accepted 05 September 2012 


\section{INTRODUCTION}

Enteric fever is a systemic infection caused by the human-adapted pathogens Salmonella enterica serotype Typhi and Salmonella enterica serotype Paratyphi A, B, and rarely, C. These organisms are important causes of febrile illness in crowded and impoverished populations with inadequate sanitation that are exposed to unsafe water and food. ${ }^{1}$ Enteric fever continues to be a global health problem with an estimated 12 to 33 million cases occurring worldwide each year. ${ }^{2}$

Traditional drugs such as chloramphenicol, ampicillin and co-trimoxazole were the most effectively used first line drugs for the treatment of enteric fever. ${ }^{3}$ However, during the late 1980s and early 1990s the occurrence of multidrug-resistant (MDR) $S$. Typhi and $S$. Paratyphi strains resistant to chloramphenicol, ampicillin and co-trimoxazole, led us to the use of fluoroquinolones, particularly ciprofloxacin and third generation cephalosporins for the treatment of enteric fever. ${ }^{4}$ The widespread use of fluoroquinolones led to increased rates of Salmonella enterica strains with reduced susceptibility to fluoroquinolones (ranged from 0.125 to $1.0 \mu \mathrm{g} / \mathrm{ml}$ ) that were being reported more frequently, particularly in Europe, Asia, and Africa. ${ }^{5}$ Nepal faced a series of enteric fever epidemics over the last decade with changing resistance patterns. ${ }^{6,7}$ In the following years, nalidixic acid-resistant strains associated with the reduced susceptibility to fluoroquinolones have been continuously reported. 6,8

Reduced susceptibility to fluoroquinolones not being detected by disc diffusion tests, even strains are still considered susceptible according to the Clinical and Laboratory Standards Institute (CLSI) interpretive criteria led to discussion regarding whether the current fluoroquinolones breakpoint criteria used for Salmonella spp. remain appropriate. ${ }^{9}$ The use of nalidixic acid disc diffusion test has been recommended by CLSI to screen reduced susceptibility to fluoroquinolones. ${ }^{10}$ Although fluoroquinolones, if susceptible, clinicians should be aware of the possibility of the treatment failures of infections with $S$. Typhi and $S$. Paratyphi A strains. ${ }^{9}$ So, it is important to monitor the increases in the MIC of fluoroquinolones in $S$. Typhi and emerging strains of $S$. Paratyphi A. ${ }^{17}$ Therefore, the present study was undertaken to evaluate the antibiotic susceptibility pattern of isolated Salmonella spp. from blood with in-depth analysis of ciprofloxacin resistance. We also investigated the relevance of using nalidixic acid resistance as a surrogate marker of fluoroquinolone susceptibility.

\section{MATERIALS AND METHODS}

The study was carried out prospectively at KIST Medical College Teaching Hospital during January 2011 to August 2011. A total of 840 blood samples of suspected enteric fever patients were included. Bacterial identifications were done using standard biochemical tests and serotyping was performed by slide agglutination test using specific Salmonella anti-Vi and anti-D antisera (CLINAG, Thailand). Antibiotic susceptibility of the isolates was determined using Kirby-Bauer disc diffusion method. ${ }^{10}$ Antibiotic discs tested were ampicillin $(10 \mu \mathrm{g})$, nalidixic acid $(30 \mu \mathrm{g})$, ofloxacin $(5 \mu \mathrm{g})$, ciprofloxacin $(5 \mu \mathrm{g})$, ceftriaxone $(30 \mu \mathrm{g})$, cotrimoxazole $(25 \mu \mathrm{g})$ and chloramphenicol $(30 \mu \mathrm{g})$. Minimum inhibitory concentration (MIC) of ciprofloxacin for Salmonella spp. isolates was determined by an agar dilution method as per CLSI guidelines. ${ }^{10}$ Twelve different concentrations of ciprofloxacin solution $(128,64,32,16,8,4,2,1,0.5$, $0.25,0.125,0.0625 \mu \mathrm{g} / \mathrm{ml}$ ) were prepared for MIC determination. The lowest concentration of the drug that gave no growth was recorded as the MIC of the ciprofloxacin to the test isolate. Ethical clearance was taken from institutional review borad. Statistical analysis was done by using Statistical Package for the Social Sciences version 18.0 (SPSS v19).

\section{RESULTS}

Out of 840 blood samples, 64 (7.6\%) yielded Salmonella spp. of which, $41(64.1 \%)$ isolates were $S$. Typhi and $23(35.9 \%)$ isolates were $S$. Paratyphi A. The age of patients under the investigation ranged from 1 month to 70 years (mean 23.43 years). The age group 15-60 years consisted maximum (78.1\%) enteric fever cases. All the isolates were sensitive to ceftriaxone and ofloxacin. Two isolates of $S$. Typhi and 2 isolates of $S$. Paratyphi A were resistant to ciprofloxacin. Only 2 isolates of Salmonella were MDR. One nalidixic acid resistant (NAR) isolate of $S$. Typhi and $S$. Paratyphi A were MDR (MDR-NAR). Fifty five isolates of Salmonella were resistant to nalidixic acid with higher rate in $S$. Paratyphi A (91.3\%) compared to $S$. Typhi (82.9\%) (Table1).

The highest MIC value of ciprofloxacin for Salmonella spp. was $8 \mu \mathrm{g} / \mathrm{ml}$ and the lowest was $0.125 \mu \mathrm{g} / \mathrm{ml}$. Out of the 41 isolates of $S$. Typhi, 2 $(4.9 \%)$ isolates were resistant and 2 (4.9\%) showed reduced susceptibility to ciprofloxacin. Out 
Table 1. Antimicrobial susceptibility pattern of $S$. Typhi and $S$. Paratyphi A

\begin{tabular}{|c|c|c|c|c|c|}
\hline \multirow[t]{2}{*}{ S.N. } & \multirow[t]{2}{*}{ Antibiotics } & \multicolumn{2}{|c|}{ S. Typhi $(\mathrm{n}=41)$} & \multicolumn{2}{|c|}{$S$. Paratyphi A $(\mathrm{n}=23)$} \\
\hline & & S (\%) & R (\%) & S (\%) & $\mathrm{R}(\%)$ \\
\hline 1 & Ampicillin & $39(95.1)$ & $2(4.9)$ & $22(95.7)$ & $1(4.3)$ \\
\hline 2 & Chloramphenicol & $40(97.6)$ & $1(2.4)$ & $22(95.7)$ & $19(82.6)$ \\
\hline 4 & Ceftriaxone & $41(100)$ & - & $23(100)$ & - \\
\hline 5 & Ciprofloxacin & $39(95.1)$ & $2(4.9)$ & $21(91.3)$ & $2(8.7)$ \\
\hline 6 & Ofloxacin & $41(100)$ & - & $23(100)$ & - \\
\hline 7 & Nalidixic acid & $7(17)$ & $34(82.9)$ & $2(8.7)$ & $21(91.3)$ \\
\hline
\end{tabular}

Note: S-sensitive; R-resistant

Table 2. MIC of ciprofloxacin and nalidixic acid screening test for $S$. Typhi and $S$. Paratyphi A

\begin{tabular}{|c|c|c|c|c|c|c|c|}
\hline \multirow[t]{2}{*}{$\begin{array}{l}\text { MIC } \\
(\mu \mathrm{g} / \mathrm{ml})\end{array}$} & \multicolumn{2}{|c|}{ S. Typhi $(\mathrm{n}=41)$} & \multirow{2}{*}{$\begin{array}{c}\text { Sensitivity } \\
\text { pattern for } \\
\text { ciprofloxacin }\end{array}$} & \multicolumn{2}{|c|}{$\begin{array}{c}\text { S. Paratyphi A } \\
(\mathrm{n}=23)\end{array}$} & \multirow{2}{*}{$\begin{array}{c}\text { Sensitivity } \\
\text { pattern for } \\
\text { ciprofloxacin }\end{array}$} & \multirow[t]{2}{*}{$\begin{array}{l}\text { MIC breakpoint } \\
(\mu \mathrm{g} / \mathrm{ml})\end{array}$} \\
\hline & NAS & NAR & & NAS & NAR & & \\
\hline 0.125 & 1 & - & \multirow{4}{*}{$\begin{array}{c}\text { Sensitive } \\
(\mathrm{n}=37) \\
90.2 \%\end{array}$} & 1 & - & \multirow{4}{*}{$\begin{array}{c}\text { Sensitive } \\
\quad(n=) \\
91.3 \%\end{array}$} & \multirow{4}{*}{$\begin{array}{l}\text { Sensitive: } \\
\leq 1 \mu \mathrm{g} / \mathrm{ml}\end{array}$} \\
\hline 0.25 & 3 & 7 & & 1 & 2 & & \\
\hline 0.5 & 3 & 19 & & - & 12 & & \\
\hline 1 & - & 4 & & - & 5 & & \\
\hline 2 & - & 2 & $\begin{array}{l}\text { Intermediate } \\
(\mathrm{n}=2), 4.9 \%\end{array}$ & - & - & & $\begin{array}{l}\text { Intermediate: } \\
>1-<4 \mu \mathrm{g} / \mathrm{ml}\end{array}$ \\
\hline 4 & - & 1 & \multirow{2}{*}{$\begin{array}{c}\text { Resistant } \\
(\mathrm{n}=2), 4.9 \%\end{array}$} & - & - & \multirow{2}{*}{$\begin{array}{c}\text { Resistant } \\
(\mathrm{n}=2), 8.7 \%\end{array}$} & \multirow{2}{*}{$\begin{array}{l}\text { Resistant: } \\
\geq 4 \mu \mathrm{g} / \mathrm{ml}\end{array}$} \\
\hline 8 & - & 1 & & - & 2 & & \\
\hline Total & 7 & 34 & & 2 & 21 & & \\
\hline
\end{tabular}

NAR- Nalidixic acid resistant; NAS- Nalidixic acid sensitive

of the 23 isolates of $S$. Paratyphi A, 2 (8.7\%) isolates were resistant to ciprofloxacin (Table 2). Salmonella isolates having MIC $\geq 1 \mu \mathrm{g} / \mathrm{ml}$ showed full nalidixic acid resistance whereas isolates having MIC $\leq 1 \mu \mathrm{g} / \mathrm{ml}$ showed resistant and sensitive to nalidixic acid The difference in mean ciprofloxacin MIC in NAR $S$. Typhi and NAR $S$. Paratyphi A was statistically significant $(\mathrm{p}<0.001)$ (Table 2). Two isolates of $S$. Typhi which were susceptible to ciprofloxacin in the disc diffusion test showed reduced susceptibility to ciprofloxacin in the MIC test (Table 1 and 2).

\section{DISCUSSION}

Lack of the growth in blood culture in this study $(64 / 840)$ resulting low isolation of the pathogens is common mainly because of use of antibiotics prior to blood collection for culture as availability and misuse of antibiotics even for mild cases of fever is common in Nepal.7,12 The blood culture positive rate was the highest $(78.1 \%)$ in the age group 15 60 years. This finding is similar to the previous study in Nepal. ${ }^{13}$

Rate of isolation of $S$. Typhi and $S$. Paratyphi A in our study was $64.1 \%(\mathrm{n}=41)$ and $35.9 \%(\mathrm{n}=23)$ respectively which is unlike the study by Maskey et al from Nepal.6 A study from Indonesia proposed that the involvement of paratyphoid fever was associated with flood and contaminated street vendor's food and typhoid fever was associated with household contamination. ${ }^{14}$ So we believe that most of the patients included in our study were not associated with flood and water contamination.

This study found that only $2(3.1 \%)$ of the isolates were MDR. An interesting observation in the present study is that MDR in $S$. Typhi has come down to $3.1 \%$ in comparison to previous studies. ${ }^{6,15}$ Both MDR isolates showed resistance to ampicillin, chloramphenicol, cotrimoxazole and nalidixic acid (MDR-NAR). The current low frequency of MDR $S$. Typhi isolates suggests that it may be possible to use first-line antibiotics again 
for the treatment of enteric fever.

All MDR isolates and isolates with resistance to ciprofloxacin were fully susceptible to cephalosporin (ceftriaxone) and ofloxacin. Ceftriaxone remains the last line drug against infections with ciprofloxacin resistant Salmonella which is also resistant to other first line drug. The use of this drug in the empiric therapy, misuse, and overuse should be discouraged.

In the present study, rate of nalidixic acid resistance, which is a phenotypic marker for reduced susceptibility to fluoroquinolones was high. S. Paratyphi A isolates showed higher rate (91.3\%) of nalidixic acid resistance than $S$. Typhi (82.9\%).In a hospital based study from Nepal in 2003, 49\% isolates of $S$. Typhi and $86 \%$ of $S$. Paratyphi A were resistant to nalidixic acid. ${ }^{6}$ In another study carried out in Nepal in 2005, it was found that $73.3 \%$ and $94.9 \%$ of $S$. Typhi and $S$. Paratyphi A isolates showed resistance to nalidixic acid. ${ }^{13}$ The emergence of these isolates is worrying given that ciprofloxacin is the most widely used antibiotics for the treatment of enteric fever in Nepal, where it is available from pharmacies without prescription by physicians.

In our study it was observed that the minimum MIC value for both Salmonella isolates was $0.125 \mu \mathrm{g} / \mathrm{ml}$ and the maximum MIC value was $8 \mu \mathrm{g} / \mathrm{ml}$. S. Typhi isolated from Dharan, during 2004, all $(n=52)$ isolates were sensitive to ciprofloxacin showing MIC $>0.25 \mu \mathrm{g} / \mathrm{ml} .{ }^{18}$ At the National Salmonella and Escherichia Center, India during 2003 to 2006, $15 S$. Typhi had minimum MIC $0.0625 \mu \mathrm{g} / \mathrm{ml}$ and maximum $1 \mu \mathrm{g} / \mathrm{m}^{16}$ So it is clearly seen that the MIC range of ciprofloxacin on Salmonella isolates is increasing i.e. sensitivity of Salmonella for ciprofloxacin is steadily decreasing. If this continues, very soon we will be dealing with enteric fever pathogens with a high MIC of ciprofloxacin.

In our study, higher percentage of ciprofloxacin resistant $S$. Paratyphi A was found. In Patan Hospital during 1993 to 2003, MICs of ciprofloxacin for $S$. Paratyphi A were higher than for $S$. Typhi, (0.75 Vs $0.38 \mu \mathrm{g} / \mathrm{ml}){ }^{6}$ Enteric fever diagnosed at India, from 2001 to 2003, complete resistance to ciprofloxacin (MIC>4 $\mu \mathrm{g} / \mathrm{ml}$ ) was detected in only two isolates, both $S$. Paratyphi A. ${ }^{17}$ Hence different literature reviews reveal that infection by and resistance of $S$. Paratyphi A are on the rise.
Salmonella isolates having MIC $\geq 1 \mu \mathrm{g} / \mathrm{ml}$ were fully NA resistant whereas isolates having MIC $\leq 1$ $\mu \mathrm{g} / \mathrm{ml}$ were resistant and susceptible to NA. This revealed that screening for NA resistance led to the detection of all isolates with MIC of ciprofloxacin $\geq 0.25 \mu \mathrm{g} / \mathrm{ml}$. The emergence of new quinolone resistance pattern in Salmonella enterica which are susceptible to NA but exhibit reduced susceptibility to ciprofloxacin was also reported from South Asia. ${ }^{8}$

$S$. Typhi and $S$. Paratyphi A with reduced susceptibility to fluoroquinolones and resistance to nalidixic acid require higher MICs of ciprofloxacin and other fluoroquinolones, ${ }^{9}$ although they are still considered susceptible according to current CLSI interpretive criteria. In our study, the 2 isolates of $S$. Typhi which were susceptible to ciprofloxacin in disc diffusion test showed reduced susceptibility to ciprofloxacin in the MIC test. Thus it was noticed that as long as the MIC of ciprofloxacin is in the intermediate range, disc diffusion test for antibiotic susceptibility didn't give a correct picture. It is hence noteworthy that MIC determination of ciprofloxacin against $S$. Typhi and $S$. Paratyphi A would help to identify the resistant isolates. However, performing MIC for every isolate in a routine Microbiology laboratory is a time consuming and labor intensive. Hence screening with nalidixic acid disc is advocated to detect the intermediately susceptible strains to ciprofloxacin.

\section{CONCLUSIONS}

Testing for resistance at currently accepted CLSI breakpoints for ciprofloxacin could result in reduced susceptibility to the drug not being detected. These isolates had all been reported as susceptible with the disc diffusion test. The current study suggests that in such cases nalidixic acid screening and determination of MICs of ciprofloxacin should be performed as per the convenience.

\section{ACKNOWLEDGEMENTS}

We gratefully acknowledge the support provided by the KIST Medical College Teaching Hospital, Imadol, Lalitpur, Nepal.

CONFLICT OF INTEREST: None to declare.

FINANCIAL INTEREST: None to declare. 


\section{REFERENCES}

1. Crump JA, Luby SP, Mintz ED. The global burden of typhoid fever. Bull Wld Heal Org 2004;82:346-353.

2. Davey PG. 2000. Available from: http://EzineArticles. Accessed July 2012.

3. Bhan MK, Bahl R, Bhatnagar S.Typhoid and paratyphoid fever. Lancet 2005;366:749-762.

4. Threlfall EJ, Ward LR, Rowe B, Raghupathi S, Chandrasekaran V. Widespread occurrence of multiple drug resistant Salmonella typhi in India. Eur J Clin Microbiol Infect Dis 1992;11:990-993.

5. Molbak K, Gerner-Smidt P, Wegener HC. Increasing quinolone resistance in Salmonella enterica serotype Enteritidis. Emerg Infect Dis 2002;8:514-515.

6. Maskey AP, Basnyat B, Thwaites GE, Campbell JI, Farrar JJ, Zimmerman MD. Emerging trends in enteric fever in Nepal: 9124 cases confirmed by blood culture 1993-2003. Trans R Soc Trop Med Hyg 2008;102:91-95.

7. Malla S, Kansakar P, Serichantalergs O, Rahman, M, Basnet S. Epidemiology of typhoid and paratyphoid fever in Kathmandu: two years study and trends of antimicrobial resistance. J Nep Med Assoc 2005;44:18-21. 8. Shirakawa T, Acharya B, Kinoshita S, Kumagai S, Gotoh A, Kawabata M. Decreased susceptibility to fluoroquinolones and gyrA gene mutation in the Salmonella enterica serovar Typhi and Paratyphi A isolated in Katmandu, Nepal, in 2003. Diag Microbiol Infect Dis 2006;54:299-303.

9. Crump JA, Youssef FG, Luby SP. Estimating the incidence of typhoid fever and other febrile illnesses in developing countries. Emerg Infect Dis 2003;9:539-544.

10. Clinical and Laboratory Standards Institute (CLSI). Performance Standards for Antimicrobial Susceptibility Testing, 16 $6^{\text {th }}$ Informational Supplement, vol. 26. Wayne, PA: CLSI, 2011; M100-S16.

11. Woods CW, Murdoch DR, Zimmerman MD, Glover WA, Basnyat B. Emergence of Salmonella enterica serotype Paratyphi A as a major cause of enteric fever in Kathmandu, Nepal. Trans R Soc Trop Med Hyg 2006;100:1063-1067.

12. Parry CM, Hoa NT, Diep TS, et al. Value of a singletube Widal test in diagnosis of typhoid fever in Vietnam. J Clin Microbiol 1999;37:2882-2886.

13. Neopane A, Singh SB, Bhatta R, Dhital B, Karki DB. Changing spectrum of antibiotic sensitivity in enteric fever. Kath Uni Med J 2008;21:12-15.

14. Woods CW, Murdoch DR, Zimmerman MD, et al. Emergence of Salmonella enterica serotype Paratyphi A as a major cause of enteric fever in Kathmandu, Nepal. Trans R Soc Trop Med Hyg 2006;100:1063-1067.

15. Pokharel BM, Koirala J, Dahal RK, Mishra SK, Khadga PK, Tuladhar NR Multidrug-resistant and extendedspectrum beta-lactamase (ESBL)-producing Salmonella enterica (serotypes Typhi and Paratyphi A) from blood isolates in Nepal: surveillance of resistance and a search for newer alternatives. Int J Infect Dis 2006;10:434-438.

\section{Citing this article}

Adhikari D, Acharya D, Shrestha P, Amatya R. Ciprofloxacin susceptibility of Salmonella enterica serovar Typhi and Paratyphi A from blood samples of suspected enteric fever patients. Int J Intfect Microbial 2012;1(1);9-13. 